\title{
NORMAL OCULAR STRUCTURE OF DROMEDARY CAMEL (CAMELUS DROMEDARIES): GROSS, ULTRASONOGRAPHIC AND COMPUTED TOMOGRAPHIC STUDY
}

\author{
BAHAA ABEDELLAAH ${ }^{1}$; AHMED SHARSHAR ${ }^{2}$; KHALED SHOGHY ${ }^{3}$ and REDA RASHED ${ }^{3}$ \\ ${ }^{1}$ Department of Surgery, Anesthesiology and Radiology, Faculty of Vet. Med. Sohag University, Egypt \\ ${ }^{2}$ Department of Surgery, Anesthesiology and Radiology, Faculty of Vet. Med. University of Sadat City, Egypt \\ ${ }^{3}$ Department of Anatomy and Embryology, Faculty of Vet. Med. University of Sadat City, Egypt
}

Received: 29 March 2017; $\quad$ Accepted: 30 April 2017

\begin{abstract}
The camel eye is studied by mean of ultrasound (US), computed topography (CT) and grossly. US was performed by micro convex probe on B-mode either by transcorneal and transpalpebral techniques and the appearance was described and ocular dimensions were recorded. Ocular sonographic appearance found similar to other species and the optic nerve appeared as a hypoechoic circular area next to the vitreous body at the far field of the image. Biometrically, the cornea was thicker at the center than the periphery, lens diameter is more than thickness and the depth of vitreous body is less than the axial length of the globe. CT images showed eye globe nearly radiolucent with some slightly radiopaque shades, the lens appeared as a highly opaque rounded spot, the bony orbit seen as an opaque rim encircling the globe and communicate with the nasal sinus medially at level of the medial canthus. Grossly, the upper cilia were longer than the lower, tactile hairs seen on the medial canthus, fat tissue present in the eyeball, cornea and pupil were oval, presence of structure on the iris resembles granula iridica in equine and the tapetum is absent.
\end{abstract}

Key words: Camel, Ultrasound, Computed Tomography, Eye.

\section{INTRODUCTION}

Compared with the other species, the camel is less studied in spite of his remarkable services in our developing countries. He aids in work and used as a source of important products for the desert inhabitants (Tibary and Anouassi, 1996; Kassab, 2012) and used as a racing animal in the Arabian Gulf region (Eltahir et al., 2010). This animal has sharp eyesight and some distinctive ocular anatomical features (Yadegari et al. (2013).

Both of ultrasound (US) and computed tomography (CT) are used to evaluate the eye. Ultrasonography is the first choice indicated for assessment of the normal eye and its orbit (Dudea, 2011). The cornea, iris, pupil, anterior chamber, vitreous body, lens, posterior wall of the globe, optic nerve and orbital bones, all can be assessed sonographically (Leo and Carmody,

Corresponding author: Dr. BAHAA ABEDELLAAH E-mail address: bahaa212121@yahoo.com

Present address: Department of Surgery, Anesthesiology and Radiology, Faculty of Vet. Med. Sohag University, Egypt
2011). Also, CT can be applied to scan the optic tissues; it is a reliable non-invasive imaging modality useful to assess the anatomically complex parts like the head (Frazho et al., 2008). It can provide crosssectional and three-dimensional images of the eye and orbital cavity (Dennis, 2000, Smallwood et al., 2002).

The current study is an attempt to describe the normal ultrasonography, CT and gross anatomy of the eye globe and orbit in the one humped camel aiming to throw light on the eye of these scientifically neglected animals.

\section{MATERIALS AND METHODS}

\section{Ultrasonographic study:}

Five adults' and clinically healthy dromedary camels (three males and two females with age ranged from 7 to 10 years old) with no history or clinical signs of eye problems were included in this study. The camels were restrained in sternal position and sedated by intramuscular injection of xylazine ( $2 \%$ xylazine hydrochloride "xylaject"; ADWIA, 10th of Ramadan City, Egypt) at dose of $0.2 \mathrm{mg} / \mathrm{kg}$. Corneal analgesia was achieved by topical application of lidocaine hydrochloride (2\% lidocaine hydrochloride "Debocaine"; EL-Debeky Egypt). 
The act of ultrasonography was performed by micro convex probe on B-mode either by transcorneal and transpalpebral techniques. Transpalpebral scanning was done parallel and perpendicular to the palpebral fissure (Nyland and Mattoon, 1995) and transcorneal scanning was preceded by the same sequence.

Ultrasonographic appearance was described. The dimensions of the globe and intraocular structures including; the central corneal thickness (CCT), the peripheral corneal thickness (PCT), depth of the anterior chamber (DAC), lens thickness (LT), lens diameter (LD), depth of the vitreous (DV) and the axial length (AL) of the eye were recorded. The latter was measured as the sum of DAC, LT and DV or the distance from between the echoes from the posterior corneal membrane and the inner rim of the retinachoroid sclera complex (Kassab, 2012, El-Tookhy el al., 2012 and Yadegari et al., 2013). The obtained values were recorded for the right and the left eyes.

\section{Computed tomographic(CT) study:}

Two camels head were collected from the slaughter house. The animals were 7 and 12 years old. CT scanning (Toshiba CT scan unit) was performed within one hour of animal slaughter. The radiological characters of the components of the eyes and the orbit were studied and described.

\section{Anatomical study:}

Three pairs of eyes obtained from adult camels were fixed in $10 \%$ formalin, dissected and the layers of the eye were studied grossly.

The results were collected and interpreted

\section{RESULTS}

Grossly, the cilia of upper eyelid are longer than lower eyelid. There are numerous tactile hairs up the medial canthus of the eye. There is fat tissue in the ventral, ventromedial and dorsomedial parts of the eyeball. The cornea and pupil of camel eye are oval in shape, yet the medial poles are more extensive. The third eyelid covers a part of the cornea. The iris has a few folds in the dorsal border of iris. The tapetum is absent in the camel eye (Fig.1).

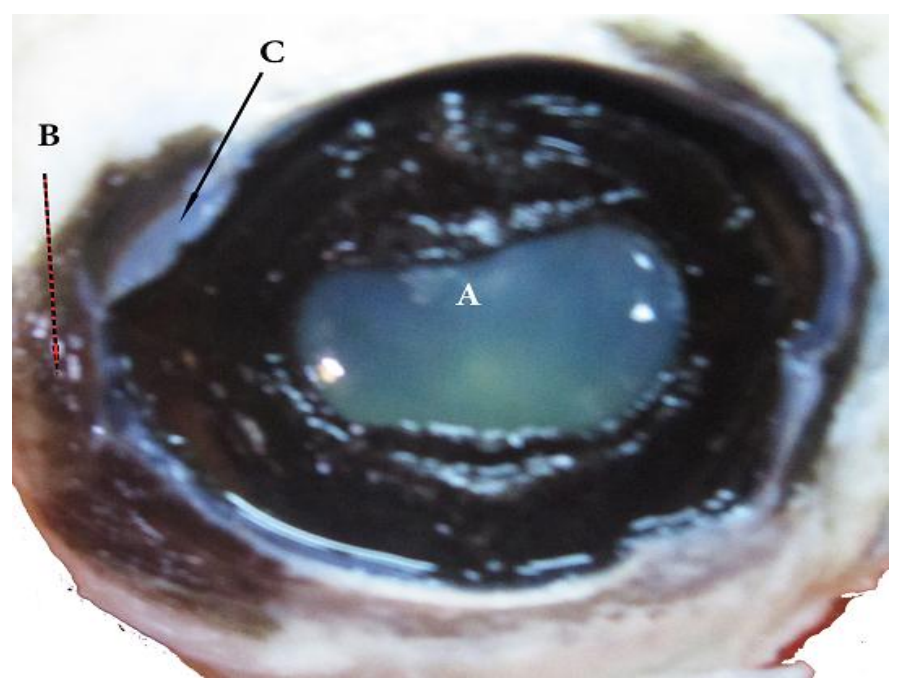

Fig. 1: The gross anatomical appearance of the camel eye

(A: structure resembles granula iridica in equine, B: third eyelid, C: cornea cut edge)

In B-mode ultrasonographic examination, the camel eye appeared spherical to slightly ovoid structure of mixed echogenicity. The anterior and posterior corneal membrane, the anterior and posterior lens capsule and the retina-choroid sclera complex were easily seen as hyper echoic linear structures. The cornea can be easily detected as thin three slightly convex layers. The outer and inner layers are hyper echoic and the middle layer appears hypoechoic. The aqueous and vitreous humors appeared anechoic. The lens tissue appeared anechoic in between two hyperechoic outer convex and inner concave lens capsules. The iris appeared as hyper echoic structure adjacent to the anterior lens capsule. The retinachoroid sclera complex appeared as hyper echoic concave line at the posterior margin of the eye ball. In longitudinal scan, the anterior surface of the iris showed echogenic mass (resembling granula iridica or corpora nigra in equine) which extends to cover nearly the whole pupillary margin. The optic nerve 
appeared as hypoechoic circular area next to the vitreous body at the far field of the image (Fig. 2, 3, 4 and 5).

Biometrically, the cornea is thicker at the center than the periphery in both right and left eyes. Lens diameter is more than its thickness in both eyes and the depth of vitreous body is less than the axial length of the globe. Ocular dimensions of the camel eyes (right and left) were summarized in Table (1).

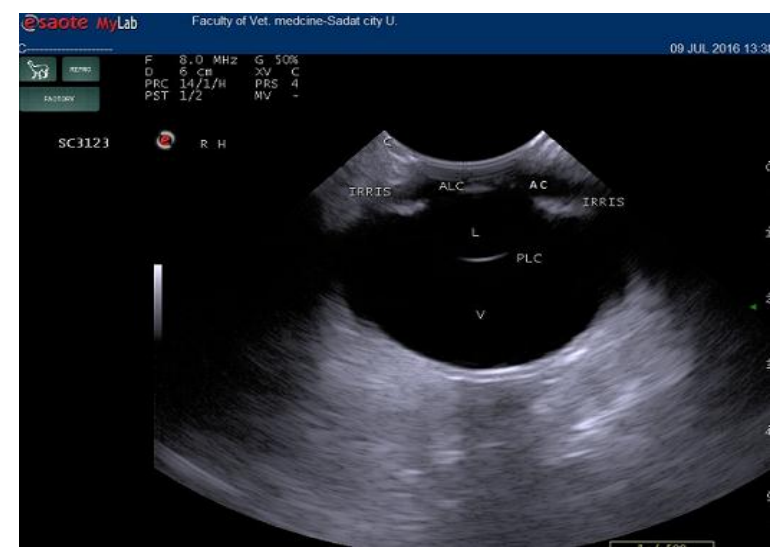

Fig. 2: Normal ultrasonography of the camel eye using microconvex probe showing; $\mathrm{C}$ : cornea, AC: anterior chamber, ALC: anterior lens capsule, L: lens, PLC; posterior lens capsule, V: vitreous body.

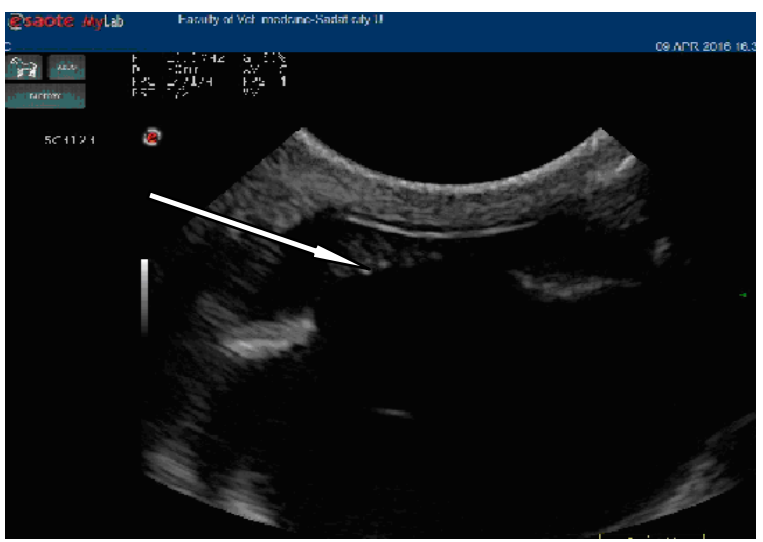

Fig.4: Normal ultrasonography of the camel eye using microconvex probe showing hyperechoic masses (arrow) on the anterior surface of the iris.

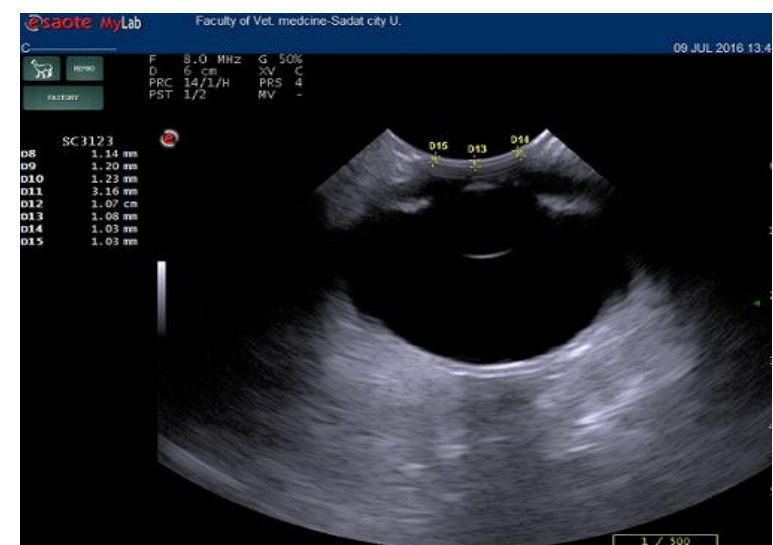

Fig.3: Normal ultrasonography of the camel eye using microconvex probe showing the measurement of the cornea.

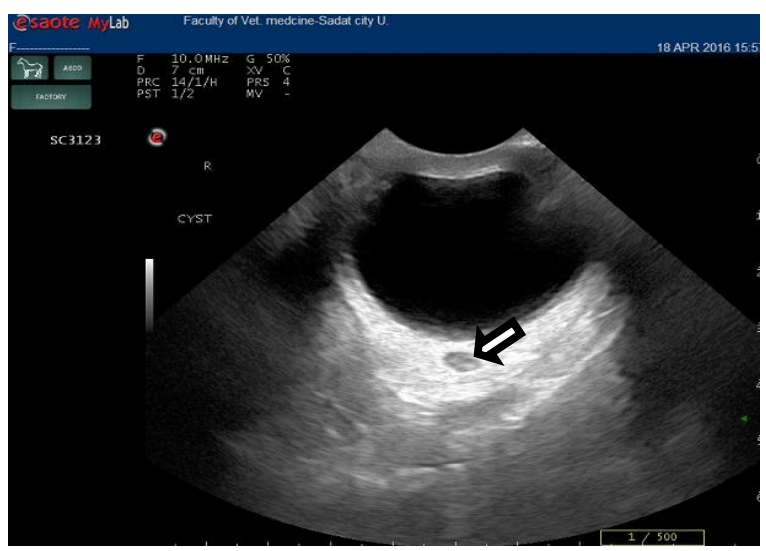

Fig. 5: Normal ultrasonography of the camel eye using microconvex probe. Notice the optic nerve appeared as a hypoechoic area next to the vitreous (arrow).

Table 1: Ultrasonographic measurements of the ocular structure of the right and left adult camel eyes

\begin{tabular}{ccc}
\hline Left & Right & Ocular structure \\
\hline $1.2 \mathrm{~mm}$ & $1.2 \mathrm{~mm}$ & CCT \\
\hline $0.99 \mathrm{~mm}$ & $1.1 \mathrm{~mm}$ & PCT \\
\hline $3.72 \mathrm{~mm}$ & $3.28 \mathrm{~mm}$ & ACD \\
\hline $1.19 \mathrm{~cm}$ & $1.21 \mathrm{~cm}$ & LT \\
\hline $1.82 \mathrm{~cm}$ & $1.96 \mathrm{~cm}$ & LD \\
\hline $1.65 \mathrm{~cm}$ & $1.56 \mathrm{~cm}$ & VD \\
\hline $3.16 \mathrm{~cm}$ & $3.1 \mathrm{~cm}$ & AL \\
\hline
\end{tabular}

CCT: Central corneal thickness, PCT: Peripheral corneal thickness, ACD: Anterior chamber depth, LT: Lens thickness, LD: Lens diameter, VD: Vitreous depth, AL:Aaxial length 
On computed tomographic images, the eye globe appears nearly radiolucent with some slightly opaque shades. A highly opaque rounded spot appears to represent the lens, it is seen in all plans (longitudinal, transverse and axial) when the scanning at its level. The bony orbit is seen clearly as a radiopaque rim encircling the eye globe. It appears complete in some

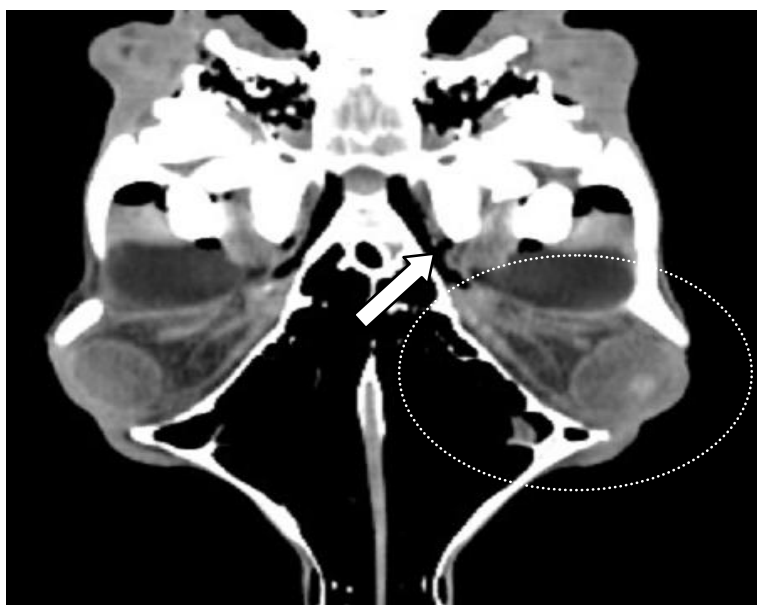

Fig. 6: Dorsal CT image of camel head. Note the connection between the orbit and the cranium (arrow).

\section{DISCUSSION}

Proofing concept that the camel has long distance vision may need advanced studies, not only because the less priority for scientific study of camel now time but also for his relatively limited distribution over land. Really, the role of camel as a work animal is diminished with the development of civilization but according to Tibary and Anouassi (1996), Eltahir et al. (2010) and Kassab (2012) still used as a source of important products for the desert inhabitants and as a race animal for the Arabian Gulf peoples. Our project is an intended study, hopefully, to contribute in the scientific explanation of the phenomenon. The study highlight this concept based on the gross anatomy and diagnostic imaging techniques for organ of vision.

Xylazine for sedation of camels and lidocaine as a surface corneal analgesia during ocular US exam is used in the current study and others (EL-Tookhy el al., 2012). Xylazine is used commonly as sedative in veterinary anesthesia (England and Clarke, 1996).

Grossly, the camel eye is circular and almost equivalent to that of bull. As far as relative body measure, the feline has the biggest eye, trailed by the canine, the equine, the bull, and the pig has the smallest relative eye. The camel eye is circular and almost equivalent to that of bull. The tapetum lucidum (inside the choroid) is not available in camel unlike other household species.

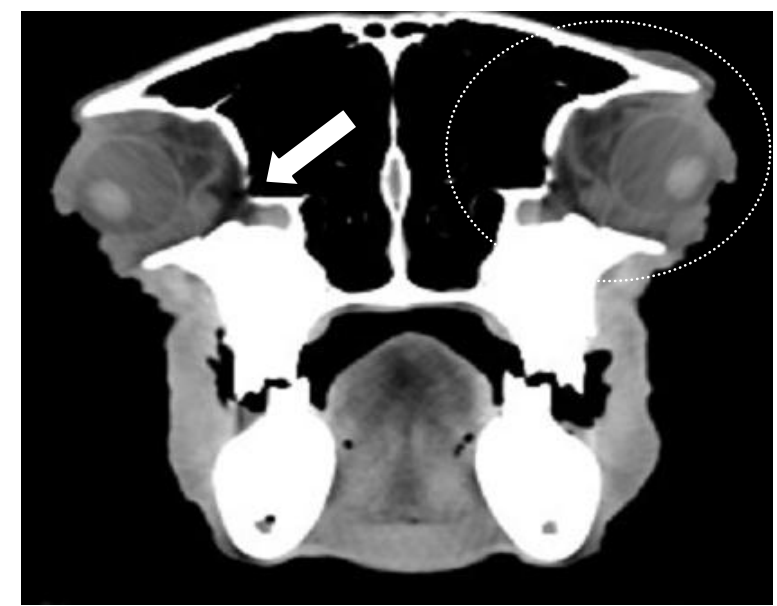

scanning levels and incomplete in others. In dorsal CT image, the communication between the orbit and the cranium is easy to identify as a disconnection in the orbital rim where the optic nerve pass from the brain (Fig. 6). In transverse CT image of camel head, the orbit appears to communicate with the nasal cavity medially at level of the medial canthus (Fig.7).

Fig. 7: Transverse CT image of camel head. Note the connection between the orbit and the nasal cavity (arrow).

Both techniques of ocular ultrasound imaging (transcorneal and transpalpebral) were applied in this study and others (Valentini et al., 2010). Both of transcorneal (Kassab, 2012; EL-Tookhy el al., 2012; Yadegari et al., 2013) and transpalpebral (Assadnassab and Fartashvand, 2013) approach can also applied. The last one make low disturbance to the animal but artifacts are common (Valentini et al., 2010). Studies found that the transcorneal one is the best concerning with image quality (Read and Barnett, 1995).

Ultrasonographic appearance of the camel eye nearly identical to that described for buffalo (Assadnassab G and Fartashvand M, 2013), horse (Reef, 1998), cattle (El-Maghraby et al., 1995; Potter et al., 2008), goat (Ribeiro et al., 2009) and dog (Kealy and McAllister, 2000). A hypoechoic area was seen next to the vitreous body at the far field of the image. This area is confirmed by the gross dissection to represent the optic nerve.

Ultrasonography revealed presence of echogenic mass on the dorsal surface of the iris which may be the first time to be recorded in camel eye (Kassab, 2012; El-Tookhy et al., 2012; Yadegari et al., 2013). Grossly, it was appeared as few folds at the dorsal surface of the iris extend along its dorsal pupillary margin. Such structure resembles granula iridica previously described in equine eyes (Seco Diaz, 2004; Valentini et al., 2010; Miller, 2015) but may need to confirm histologically. According to our 
opinion, this structure may be important to provide shade to the eye and protect the lens and structure at the posterior eye segment (i.e. retina and choroid) from direct exposure to sun light (Samuelson, 2007 and Miller, 2015), especially, most camels lives at the desert spending the majority of their life outdoors in grazing and traveling in direct sun light.

Also, CT soft tissue window offer to us to describe, clearly, the internal structures of the eye globe which appeared nearly radiolucent with some slightly radiopaque shades. This lucent appearance is the shadow of aqueous fluids in anterior chamber and acellular gel in the posterior segment (Getty, 1975). The radiopacity of the lens on computed tomography may come from its components. It is composed of a capsule, anterior epithelium, lens fibers and nucleus (Penninck and d'Anjou, 2013).

\section{CONCLUSION}

After studying the camel eye anatomically, ultrasonographically and with computed tomography, it can be concluded that such eye nearly similar to that's of other species with some peculiar features. Firstly, the presence of folds (resembles granula iridica in equine) in the dorsal border of iris that is appeared sonographically as an echogenic mass and secondly, the optic nerve could be seen clearly as a hypoechoic circular area next to the vitreous body at the far field of the image. We can speculate that such features may assist to improve the sharpness of vision of camel and to protect the lens and structures at the posterior eye segment from direct exposure to sun light regarding to most camels lives at the desert in the direct sun light either in grazing and/or traveling.

\section{REFERENCES}

Assadnassab, G. and Fartashvand, M. (2013): Ultrasonographic evaluation of buffalo eyes. Turk J Vet Anim Sci; 37: 395-398.

Dennis, R. (2000): Advanced imaging: indications for CT and MRI in veterinary patients. In Pract.; 25: $243-254$.

Dudea, S.M. (2011): Ultrasonography of the eye and orbit. Medical Ultrasonography; 13 (2): 171174.

El-Maghraby, H.; Nyland, T.G. and Bellhorn, R.W. (1995): Ultrasonographic and biometric evaluation of sheep and cattle eyes. Vet. Radiol. Ultrasound; 36: 148-151

Eltahir, Y.E.; Ali, H.M.; Mansour, M.H. and Mahgoub, O. (2010): Serum Mineral Contents of the Omani Racing Arabian Camels (Camelus dromedaries). Journal of Animal and Veterinary Advances; 9 (4): 764-770.
El-Tookhy, O.; Al-Sobayil, F.A. and Ahmed, A.F. (2012): Normal ocular Ecobiometry of the Dromedary camels. Journal of Camel Practice and Research; 19 (1): 13-17.

England, G.C.W. and Clarke, K.W. (1996): Alpha 2 adrenoreceptor agonists in the horse. A review. Br. Vet. J; 152: 641-657.

Frazho, J.K.; Tano, C.A. and Ferrell, E.A. (2008): Diagnosis and treatment of dynamic closed mouth jaw locking in a dog. JAVMA; 233: 748-751.

Getty, R. (1975): Sisson and Grossman's The Anatomy of the Domestic Animals, $5^{\text {th }}$ Ed. WB Saunders Co, Philadelphia: 1350-1352.

Kealy, J.K. and McAllister, H. (2000): Diagnostic Radiology and Ultrasonography of the Dog and Cat. $3^{\text {rd }}$ Ed., WB Saunders Co., St. Louis: 377-378.

Leo, M. and Carmody, K. (2011): Sonography assessment of acute ocular pathology. Ultrasound Clinics of North America; 6(2): 227-234.

Kassab, A. (2012): Ultrasonographic and macroscopic anatomy of the enucleated eyes of the buffalo (Bos bubalis) and the one-humped camel (Camelus dromedarius) of different ages. Anat. Histol. Embryol; 41: 7-11.

Miller, C. (2015): Applied Ophthalmic Anatomy and How to Describe Ocular Lesions. AAEP FOCUS ON AMBULATORY PROCEEDINGS / 2015

Nyland, T.G. and Mattoon, J.S. (1995): Veterinary Diagnostic Ultrasound. $1^{\text {st }}$ Ed. WB Saunders Company, Philadelphia: 178-197.

Penninck, D. and d'Anjou, M. (2013): Atlas of Small animal Ultrasonography. Blackwell Publishing: 49-90.

Potter, T.J.; Hallowell, G.D. and Bowen, I.M. (2008): Ultrasonographic anatomy of the bovine eye. Vet. Radiol. Ultrasound; 49: 172-175.

Read, R.A. and Barnett, K.C. (1995): Equine glaucoma diagnosed with the aid of ultrasonography. Equine Vet. Educ; 7: 225228.

Reef, V.B. (1998): Equine Diagnostic Ultrasound. $2^{\text {nd }}$ Ed. W.B. Saunders Co., Philadelphia: 50-71.

Ribeiro, A.P.; Silva, M.L.; Rosa, J.P.; Souza, S.F.; Teixe-ira, I.A. and Laus, J.L. (2009): Ultrasonographic and echobiomet-ric findings in the eyes of Saanen goats of different ages.Vet. Ophthalmol; 12: 313-317.

Samuelson, D. (2007): Ophthalmic anatomy. In Gelatt K, editor : Veterinary Ophthalmology. Ames: Blackwell, 37-148.

Seco Diaz, O. (2004): Ultrasound of the Equine Eye and Adnexa and Clinical Applications. Clin Tech Equine Pract; 3:317-325.

Smallwood, J.E.; Wood, B.C.; Taylor, W.E. and Tate, L.P.Jr. (2002): Anatomic reference for 
computed tomography of the head of the foal. Vet Radiol Ultrasound; 43(2):99-117.

Tibary, A. and Anouassi, A. (1996): Ultrasonographi changes of the reproductive tract in the female camel (Camelus dromedarius) during the follicula cycle and pregnancy. Journal of Camel Practice and Research; 3: 71-90.

Valentini, S.; Tamburro, R.; Spadari, A.J.M. and Spinella, G. (2010): Ultrasonographic evaluation of equine ocular diseases: A retrospective study of 38 eyes: Journal of equine veterinary science; 30 (3): 150-154.

Yadegari, M.; Salehi, A.; Ashtari, A. and Ashtari, M.S. (2013): B-mode Ultrasound Biometry of Intraocular Structures in Dromedary Camels (Camelus dromedarius). Global Veterinaria; 10 (1): 71-74.

\section{دراسة التركيب التشريحي للعين في الجمل وحيد السنام من خلال التصوير بالموجات الفوق صوتية والأشعة المقطعية}

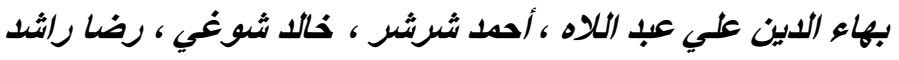

Email: bahaa212121@yahoo.com Assiut University web-site: www.aun.edu.eg

\footnotetext{
تمت در اسة عين الجمل احادي السنام تشريحيا وباستخدام التصـوير باستخدام الموجات الفوق صـوتية والاشتعة المقطعية. ووجد أنها

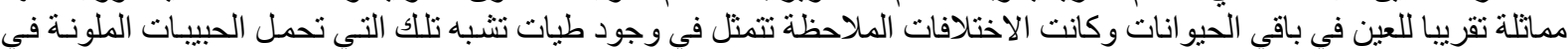

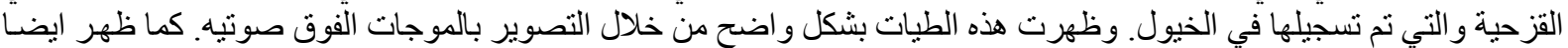

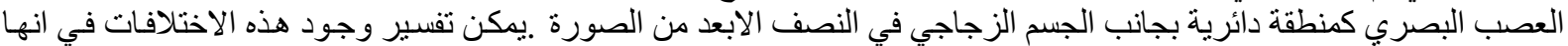

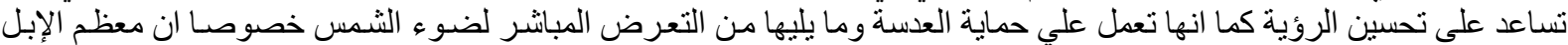

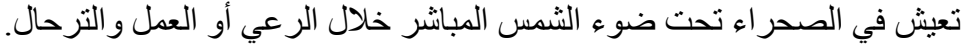

